\section{An Additional Note on American Arrowheads}

As Mr. Evans has commenced his remarks on North American arrowheads with the assertion, "A prevailing type," \&c., it naturally leads one to conclude that that form to which he refers is "the" prevailing type. I judge, further, that by "prevailing," he means "predominant," i.e., in excess of other types or shapes of these relics. I do agree with Mr. Evans that it is one of the principal forms, but not so far a "prevailing" type as to merit the assertion of Mr. Evans, made as that assertion is.

As to the leaf-shaped form, I have but to remark that, in my own collecting experience, the true leaf-shaped, i.e., the rounded-based, straight-sided, acutely-pointed form, such as Mr. Evans's Fig. 282, constitutes about $4 \frac{\mathrm{T}}{2}$ per cent. of those gathered in my own neighbourhood; and this I know to be the experience of other collectors, in other and distant localities. This, I submit, is sufficient to show that this form is not even "comparatively rare," but may be better described as "not uncommon."

And so far as workmanship is concerned, I have only to say that if narrow, thin barbs, acute points, sharp edges, and smoothness of the broad surfaces of arrowheads, constitute what has been termed "delicacy of workmanship," then the American forms in horn-stone, jasper, chert, quartz, agate, and some finelygrained slates, cannot be excelled by similar relics found elsewhere, or made from other material. "This remark I base on the specimens collected by myself here in New Jersey, which State is not the best locality, by any means, for gathering these objects; and I have found that the western, northern, yand southern specimens have excelled those I have collected here at home.

From the above paragraph $I$ have purposely omitted the mineral obsidian, because the arrowheads of this material excel all others wheresoever found, and I wish to make good my assertions without the help of Californian specimens.

I take the liberty of referring those persons interested in these matters to a large series of arrowheads collected here in New Jersey, and now in the collection of Sir John lubbock: If some of these are not equal to any English specimens, I must simply "give in."

Trenton, New Jersey, U.S.A., Oct. Io

\section{Merrifield on the Deviation of the Compass}

As a review of my little manual on "Deviation," \&c., has appeared in NATURE for October I7th, in which I am accused of having "written with looseness and inaccuracy," perhaps you will kindly allow me a small space to answer my critic. $\mathrm{He}$ has selected a most unfortunate example to bear out his assertion; and I contend for the accuracy of my statement. "Vertical iron, at the same place, will produce the same deviation in whatever direction the ship's head may be." Here I do not pretend to say (as my reviewer insinuates), that the whole devia tion is the same in every position of the ship's head; but I maintain that that part due to vertical iron remains constant for the same place until a change of secular variation becomes cog nisable. I am at a loss to discover either looseness, inaccuracy, or substitution of cause for effect in what follows, and I am inclined to think, if any exists, it must be on the part of my reviewer

Again, I am not aware of any " singular statements and conceptions" in the larger work on "Navigation and Nautical Astronomy," which are at variance with the matter contained in the small manual under consideration. Perhaps you will kindly permit my reviewer to mention some.

I grant there may be differences of opinion on the merits of any work (as is fully proved in the present instance); but when public statements are made of "inaccuracies," these should either be substantiated or withdrawn.

Navigation School, Plymouth, Oct. I9

JohN MERrifieLD

\section{Earth Currents}

IT may be interesting to record that during the past few days we have been subject to electric storms, I think I may say unparalleled in their frequency, intensity, and duration. On Oct. I4 a severe one raged from 9.30 A.M. to I P.M., and in the evening from IO.20 P.M. to past midnight. On the $15^{\text {th }}$ a still more severe one raged from $9.30 \mathrm{~A}, \mathrm{M}$. to I P.M., and in the evening from 7 P.M. to 9.5 P.M. On the $\mathrm{I} 7$ th inst. the currents were very embarrassing from II.20 A.M. to 12.45 P.M., and from 2. Io to 9.0 P.M. ; and on the 18 th they were again troublesome.

They differed but little in their character from those usually observed, the currents continually varying in intensity and duration during the periods named. The interruptions to business on the I 5 th were serious, and many stations could only be com. nunicated with by looping the wires, when more than one existed, into metallic circuits. Circuits running east and west were mostly affected, those running north and south, for instance, between London and Brighton, being but little disturbed. regret to say that no precise measurements of the strength of these currents have yet reached me.

Southampton, Oct. 2I

W. H. Prerce

\section{Aurora Borealis}

ON Saturday, Oct. 6, I was walking in our large playground with a friend, about 8.40 P.M., when we saw above us a mag. nificent red "way" whose direction was E.N.E. When we first looked, this broad band was bifurcated towards the E. end, one fork going more to the east, and the other to the north. In a minute or two this bifurcation disappeared, and in three minutes more the whole had disappeared, leaving the sky as before, It could be nothing but an aurora; at any rate, it was not the light of any fire, it was too magnificent, and for the time that it lasted of too great a length. I took no notes at the time, but feel that $I$ have given you a correct account of the phenomenon, as far as it goes.

Christ's Hospital, Oct. 20

F. JeFFrey BeLL

\section{Ocean Currents}

IT is to be regretted that the correspondents of NATURE, who for some weeks past have been writing on the subject of Ocean Currents, should ignore the consideration that it is primarily a question of geographical fact, and that any theory which runs counter to that needs no more elaborate confutation than a bare statement of the fact, supported, if necessary, by authoritative evidence. Thus, then, when we find the effect of the earth's rotation put forward, in the way it has lately been, by $\mathbf{M r}$. Ferrel and Prof. Everett, it is quite needless to examine the calculations which have been adduced; it is sufficient to say that the conclusions arrived at are contrary to geographical fact; that currents do not by any means universally turn to the right in the northern, or to the left in the southern hemisphere;-to name a few amongst many, the Gulf Stream turning to the lef round Cape Hatteras, and again towards the coast of Ireland, Rennell's current, the Agulhas current, the Cape Horn current as it turns south near Chiloe, the current through Behring's Strait, are cases in point, currents turning in a manner exactly opposite to that deduced from the theory.

Similarly, when Dr. Carpenter, whether supported or not by severai distinguished phycisists, argues from the effect of great differences of temperature in a small trough, as to the effect of much smaller differences of temperature in the incomparably larger ocean, it is unnecessary to follow him into his reasonings, for the conclusion, as he has lately stated it, that there is "necessarily an upper flow from the equator towards the poles," is geographically false. Over a very great part of the North Atlantic there is no prevailing set at all ; in the South Atlantic and in the South Pacific the set has a general though slight tendency towards the north; the East Greenland current, the North African current, the South African current, the Perivian current, and many others, run strongly towards the equator; there is nothing at all resembling a general "upper flow from the equator towards the poles."

As a question of abstract mathematics, Mr. Ferrel is undoubtedly at liberty to prove that every current in the northern hemisphere turns to the right, as much as he was, a few years ago, to prove that there is no air within some twenty or twentyfive degrees of the poles ; and as a point of experimental science, Dr. Carpenter's illustrations are pretty, and can be understood without the authority of the distinguished men whose names he brings forward; though I should be loth to believe that $M$ r. Hawksley, or any other experienced hydraulic engineer, would agree with his idea that water will always find its own level.

But the application of the mathematical problem or the experimental illustration to the case in point is quite a different thing; 